\title{
Low starting dosage of infliximab with possible escalating dosage in psoriatic arthritis gives the same treatment results as standard dosage of adalimumab or etanercept: results from the nationwide Icelandic ICEBIO registry
}

This article was published in the following Dove Press journal: Psoriasis: Targets and Therapy

\author{
Bjorn Gudbjornsson ${ }^{1,2}$ \\ Arni Jon Geirsson ${ }^{3,4}$ \\ Niels Steen Krogh ${ }^{5}$ \\ 'Centre for Rheumatology Research, \\ University Hospital, Reykjavik, Iceland; \\ ${ }^{2}$ Faculty of Medicine, University \\ of Iceland, Reykjavik, Iceland; \\ ${ }^{3}$ Department of Rheumatology, \\ University Hospital, Reykjavik, Iceland; \\ ${ }^{4}$ Laeknasetrid - Medical Clinic, \\ University of Iceland, Reykjavik, \\ Iceland; ${ }^{5}$ Zitelab Aps, Copenhagen, \\ Denmark
}

Objective: To explore differences in response to a low dosage regimen of infliximab with an escalating dosage in comparison to a standard dosage of etanercept and adalimumab in patients with psoriatic arthritis (PsA).

Methods: Biologically naïve PsA patients who were beginning anti-TNF- $\alpha$ therapy were selected from the ICEBIO registry. Demographics and clinical differences were compared in four treatment groups: infliximab $<4 \mathrm{mg} / \mathrm{kg}$; infliximab $>4 \mathrm{mg} / \mathrm{kg}$; etanercept or adalimumab at baseline and on follow-up (6 and 12 months, last visit). The Kruskal-Wallis rank sum test was used for comparison of the groups and the Wilcoxon test to compare the two infliximab dosage regimens. Results: One hundred and eighty-five patients ( $61 \%$ female) were identified; 84 patients received infliximab, 66 etanercept, and 35 adalimumab. A total of $19 \%$ of the patients treated with infliximab escalated their dosage $\geq 4 \mathrm{mg} / \mathrm{kg}$. No significant differences were observed at baseline in respect to visual analog scale (VAS) pain, VAS fatigue, Health Assessment Questionnaire, C-reactive protein (CRP), numbers of swollen or tender joints, or Disease Activity Score (DAS) 28-CRP values. A similar treatment response was observed in all four treatment groups on follow-up.

Conclusion: In respect to treatment effects, a low dosage of infliximab with possible escalating dosage is acceptable for the majority of PsA patients who are in need of biological treatment.

Keywords: psoriatic arthritis, outcome, biological treatment, routine care, clinical nationwide registry

\section{Introduction}

The prevalence of psoriatic arthritis (PsA) in Iceland is at least $0.14 \%-0.19 \%$ according to a recent publication from the Reykjavik Psoriatic Arthritis study, where the clinical manifestations are also described. ${ }^{1}$ International guidelines on the treatment strategies for PsA have been published both by EULAR (European League Against Rheumatism) ${ }^{2}$ and GRAPPA (Group for Research and Assessment of Psoriasis and Psoriatic Arthritis). ${ }^{3}$ Similar guidelines have been published nationally, e.g., in Iceland. ${ }^{4}$ Although these guidelines are very similar, there is a major difference in the Icelandic version in respect to the dosage of infliximab, i.e., the Icelandic guideline recommends an infliximab dosage of $200 \mathrm{mg}$ given on weeks $0,2,6$, and then every $8^{\text {th }}$ week, independently of body weight, with possible escalating dosage as needed
Correspondence: Bjorn Gudbjornsson Centre for Rheumatology Research, University Hospital, Hringbraut, I0I Reykjavik, Iceland Email bjorngu@landspitali.is 
according to clinical response, while most other guidelines recommend infliximab dosage of $5 \mathrm{mg} / \mathrm{kg}$. Other TNF inhibitors are given in fixed standard dosages.

The IMPACT (Infliximab Multinational Psoriatic Arthritis Controlled Trial) and the IMPACT2 trials, which both focused on patients with PsA, used protocols with 5 and $10 \mathrm{mg} /$ $\mathrm{kg}$ of infliximab, ${ }^{5,6}$ whereas previously a trial of infliximab in patients with psoriasis used 3 and $5 \mathrm{mg} / \mathrm{kg}$. ${ }^{7}$ Therefore, international guidelines recommend the dosage of infliximab to be $5 \mathrm{mg} / \mathrm{kg}$. Meanwhile, no randomized controlled studies on lower dosages have been published for PsA. However, scattered case reports reported using a lower dosage and a small series of patients with PsA have been treated with a lower dosage or $3 \mathrm{mg} / \mathrm{kg}$, i.e., according to recommendations for rheumatoid arthritis (RA). ${ }^{8-10}$ Cauza et al reported nine patients with PsA and psoriasis vulgaris who received $3 \mathrm{mg} /$ $\mathrm{kg}$ of infliximab, which was effective and well tolerated. ${ }^{8} \mathrm{In}$ 2009 Di Renzo et al asked why $3 \mathrm{mg} / \mathrm{kg}$ instead of $5 \mathrm{mg} / \mathrm{kg}$ of infliximab should not work in PsA and he also reported a case of a 38-year-old white man with body weight of $104 \mathrm{~kg}$, affected by plaque-type psoriasis and PsA, who responded well to $3 \mathrm{mg} / \mathrm{kg}$ of infliximab. ${ }^{9}$ Recently, Tenga et al reported their retrospective experience of starting $3 \mathrm{mg} / \mathrm{kg}$ in ten patients with spondyloarthritis in association with PsA. ${ }^{10}$ Furthermore, we have, together with the Danish database DANBIO, recently published that starting at a dose lower then $4 \mathrm{mg} / \mathrm{kg}$ of infliximab did not affect drug survival or treatment response in patients with PsA. ${ }^{11}$ In addition, several reports on a similar treatment regime have been published in ankylosing spondylitis (AS). ${ }^{12,13}$ Still, international guidelines recommend a dosage of infliximab $5 \mathrm{mg} / \mathrm{kg}$ for AS, as for PsA.

By using data from ICEBIO, a nationwide registry on routine use of biologics for rheumatic disorders in Iceland, we aim to explore differences in response to a low dosage regimen of infliximab with escalating dosage in comparison to a standard dosage of etanercept and adalimumab in patients with PsA.

\section{Material and methods}

Patients with PsA who were all biologically naïve and initiating their first anti-TNF- $\alpha$ therapy were selected from the ICEBIO registry. However, most of the patients have been treated with methotrexate or other disease modifying drugs before the start of their biologic therapy, but they were naïve for biologics.

ICEBIO is an Icelandic nationwide database on patients treated with biologic disease-modifying antirheumatic drugs due to inflammatory joint diseases; including RA, AS, and PsA. The database is based on the Danish Registry for
Biologic Therapies in Rheumatology, DANBIO.$^{14}$ ICEBIO started collecting data in 2007 with a prospective registration at initiation of all biologics, as well as on annual follow-up visits. Patients who started their treatment before 2007 have been registered retrospectively in ICEBIO based on their medical records. Currently, ICEBIO covers approximately $98 \%$ of all patients treated with biologics for rheumatic disorders in Iceland. On January 1, 2015, there was information available on 953 individuals in ICEBIO, of whom 222 individuals had been diagnosed with PsA.

When patients start treatment with biologics in Iceland, it is obligatory to register detailed health and disease information in ICEBIO, regardless of whether the treating physician is at the university hospital or at his/her private clinic. Standard follow-up data are then registered annually on regular visits to outpatient clinics. ICEBIO is part of the patient electronic record system, hosted by the University Hospital of Iceland. Thus, it is independent from the pharmaceutical industry.

As a standard of care, the startup dosage of infliximab was $200 \mathrm{mg}$ on weeks $0,2,4$, and then every $8^{\text {th }}$ week, independently of the body weight of the patient. Insufficient response to treatment resulted the dosage was increased stepwise by $100 \mathrm{mg}$, e.g., up to $300 \mathrm{mg}$, or $400 \mathrm{mg}$. If the dosage reached $4 \mathrm{mg} / \mathrm{kg}$ the patient was classified as having a "regular" dosage of infliximab in contrast to a low dosage regimen. Other TNF inhibitors (etanercept at $50 \mathrm{mg} /$ week and adalimumab at $40 \mathrm{mg} / 2$ weeks) were given in fixed dosages.

Demographics include age, gender, disease duration (time from confirmed diagnosis of PsA by rheumatologist and the time from the start of any symptoms that the individual patient claims that is due to his/her PsA) and current treatment with methotrexate. Functional status was monitored by Health Assessment Questionnaire (HAQ), swollen and tender 28-joint count (SJC; TJC), Disease Activity Score (DAS) 28, CRP level (normal range $\leq 10 \mathrm{mg} / \mathrm{L}$ ), and visual analog scale (VAS) for scores of pain and fatigue were collected from ICEBIO.

Clinical differences were compared in four groups: 1) those who responded to a low dosage of infliximab $(<4$ $\mathrm{mg} / \mathrm{kg}$ ); 2) those who needed to increase the dosage of infliximab above $4 \mathrm{mg} / \mathrm{kg}$; 3) those who received a standard fixed dosage of etanercept (50 mg/week); or 4) adalimumab ( $40 \mathrm{mg} / 2$ weeks). Follow-up data at 26 weeks (18-32 weeks) and 52 weeks (46-64 weeks) weeks were compared and also at the last visit at our outpatient clinic (147 weeks; [45-217 weeks]) after initiating the treatment.

Data are presented as the mean with $25 \%$ and $75 \%$ quartiles. The Kruskal-Wallis rank sum test was used for comparison of the groups and the Wilcoxon test was used to 
compare the two infliximab dosage regimens. To compare drug survival between the groups we used survdiff from $\mathrm{R}$ version 3.4.3 (R Foundation for Statistical Computing, Vienna, Austria). The National Bioethics Committee and the Data Protection Authority in Iceland approved the study protocol.

\section{Results}

A total of 185 patients, 113 women and 72 men, were identified; 84 patients received infliximab, 66 etanercept, and 35 adalimumab (Table 1). No biosimilar TNF inhibitors were in use in Iceland at the time of the study. Standard data were collected from ICEBIO from all patients at the start-up of their TNF inhibitor treatment, around 6 and 12 months follow-up, and then from their latest visit to outpatient clinics, both at the University Hospital as well as at private clinics, respectively.

The mean numbers of days (with $25 \%$ and $75 \%$ quartiles) from the start of TNF therapy to the last visit for the group of patients that received low dosage of infliximab was 1029 days $(313 ; 1366)$, for those who needed to increase the dosage of infliximab, 1363 days (408; 2162), for the etanercept group, 1040 days $(290 ; 1533)$, and for the fourth group that received adalimumab the number of days to the last visit was 967 (473; 1386), which did not reach significant differences between the groups (Kruskal-Wallis rank sum test, $p$-value 0.65).

Twenty percent of the patients (17/84) treated with infliximab had to escalate the infliximab dosage to exceed $4 \mathrm{mg} / \mathrm{kg}$. Those still on a low dosage regimen had a mean dosage of infliximab of $2.9 \mathrm{mg} / \mathrm{kg}$, but those who had escalated their dosage above $4 \mathrm{mg} / \mathrm{kg}$ had a mean dosage of $4.5 \mathrm{mg} / \mathrm{kg}$. Six patients required infliximab more frequently than at 8 -week intervals; five patients (two patients: $200 \mathrm{mg}$; three patients: $300 \mathrm{mg}$ ) received infliximab at 6-week intervals and one patient $(300 \mathrm{mg})$ on a 7 -week schedule.

At baseline those who continued with a low dosage of infliximab had a shorter disease duration (8 vs. 10 years), but a longer history of symptoms than those who needed to increase their dosage of infliximab, but neither value reached a significant difference. The patients on a low dosage of infliximab had a significantly higher body mass index than those on a higher dosage (Wilcoxon test, $p<0.01$ ).

No significant differences were observed between the four groups at baseline in respect to SJC or TJC, HAQ, VAS pain, VAS fatigue or DAS28CRP values, neither at 26, 52 nor on the last visit (Table 2). Furthermore, we analyzed the delta value of previously-mentioned valuables for each group and they did not demonstrate any significant difference between the groups (Table 3).

The adherence to treatment after 52 weeks was highest in the adalimumab group or $84 \%$, followed by the higher infliximab dose group $-81 \%$, etanercept $-75 \%$, and then the lower infliximab dose group $-68 \%$, however, it did not reach significant difference, not at 52 weeks ( $p$-value 0.31 ) nor at 104 weeks ( $p$-value 0.14$)$. Further, Figure 1 illustrates the drug survival time for the groups over a 2-year period.

\section{Discussion}

This nationwide, registry-based observational study included 185 patients with PsA who were all naïve for TNF inhibitors, but were in need of biological therapy due to active joint disease. The observation time was up to 4 years. The study indicates that in respect of treatment efficacy, a low dosage of infliximab, with starting dosage of $2.3 \mathrm{mg} / \mathrm{kg}$ with possible escalating dosage is acceptable for the majority of patients with PsA who are in need of biological treatment, and this regime seems as effective, in daily clinical practice, as treatment with other TNF inhibitors.

Although international guidelines recommend $5 \mathrm{mg} / \mathrm{kg}$ of infliximab for patients with PsA, registry studies have demonstrated that in routine care physicians seem to use a lower dosage of infliximab; e.g., a report from Sweden illustrates that the starting dose of $3 \mathrm{mg} / \mathrm{kg}^{15}$ gave good treatment

Table I Baseline demographic data

\begin{tabular}{|c|c|c|c|c|c|}
\hline & $\begin{array}{l}\text { Infliximab } \\
<4 \mathrm{mg} / \mathrm{kg}\end{array}$ & $\begin{array}{l}\text { Infliximab } \\
>4 \text { mg/kg }\end{array}$ & $\begin{array}{l}\text { Etanercept } \\
50 \mathrm{mg} / \text { week }\end{array}$ & $\begin{array}{l}\text { Adalimumab } \\
40 \mathrm{mg} / 2 \text { weeks }\end{array}$ & $\begin{array}{l}\text { p-value between } \\
\text { the groups** }\end{array}$ \\
\hline Number & 67 & 17 & 66 & 35 & \\
\hline Male, n (\%) & $30(4 I)$ & $8(47)$ & $23(35)$ & $13(37)$ & 0.8004 \\
\hline Age, years & $49(40-56)$ & $49(38-60)$ & $50(42-59)$ & $52(44-60)$ & $0.774 I$ \\
\hline Disease duration, years & $8(2-13)$ & $10(3-18)$ & $10(3-14)$ & $9(2-I I)$ & 0.4343 \\
\hline Symptom duration, years & $28(3-17)$ & $17(3-28)$ & II (5-16) & II (4-15) & 0.9135 \\
\hline $\mathrm{BMI}, \mathrm{kg} / \mathrm{m}^{2}$ & $31(27-34)^{*}$ & 27 (24-29)* & $32(27-36)$ & $30(26-33)$ & 0.0129 \\
\hline Methotrexate, \% & 38 & 40 & 39 & 41 & 0.72 \\
\hline
\end{tabular}

Notes: One hundred and eighty-five patients with psoriatic arthritis, all biologically naïve, who were treated with four different treatment strategies with TNF- $\alpha$ inhibitors. Data are presented with means and quartiles. Significant differences were observed in BMI between the two infliximab groups (Wilcoxon test: * $p<0.005 \mathrm{I}$ ). $* *$ Kruskal-Wallis rank sum test was used to compare all four groups

Abbreviation: BMI, body mass index. 
Table 2 Disease activity

\begin{tabular}{|c|c|c|c|c|c|c|c|c|}
\hline & $\mathbf{N r}$ & CRP mg/L & SJC & TJC & HAQ & VAS pain & VAS fatigue & DAS28 \\
\hline \multicolumn{9}{|l|}{ Infliximab } \\
\hline \multicolumn{9}{|l|}{$<4$ mg/kg } \\
\hline \multirow[t]{2}{*}{ Baseline } & 59 & 11.0 & 4.2 & 5.1 & 0.94 & 62 & 61 & 4.18 \\
\hline & & $3 ; 16$ & I; 6 & $2 ; 6$ & $0.4 ; 1.4$ & $48 ; 80$ & $45 ; 83$ & $3.7 ; 4.9$ \\
\hline \multirow[t]{2}{*}{26 weeks } & 34 & 7.0 & 1.5 & 2.7 & 0.57 & 36 & $4 I$ & 3.09 \\
\hline & & $3 ; 6$ & $0 ; 3$ & $0 ; 5$ & $0.1 ; 0.9$ & $18 ; 53$ & $20 ; 60$ & $2.2 ; 3.8$ \\
\hline \multirow[t]{2}{*}{52 weeks } & 18 & 8.0 & 0.9 & 2.2 & 0.62 & 43 & 49 & 3.1 \\
\hline & & $3 ; 11$ & $0 ; 1$ & $0 ; 3$ & $0.1 ; 1.0$ & $16 ; 78$ & $25 ; 70$ & $2.0 ; 3.9$ \\
\hline \multirow[t]{2}{*}{ Last visit } & 57 & 6.6 & 0.7 & 1.9 & 0.69 & 35 & 39 & 2.77 \\
\hline & & $2 ; 8$ & $0 ; 1$ & $0 ; 3$ & $0.2 ; 1.0$ & $13 ; 57$ & $16 ; 65$ & $2.0 ; 3.4$ \\
\hline \multicolumn{9}{|l|}{$>4$ mg/kg } \\
\hline \multirow[t]{2}{*}{ Baseline } & 11 & 11.2 & 3.3 & 8.9 & 1.09 & 71 & 74 & 4.49 \\
\hline & & $3 ; 14$ & $0 ; 7$ & $3 ; 16$ & $0.4 ; 1.9$ & $60 ; 87$ & $74 ; 87$ & $3.7 ; 5.2$ \\
\hline \multirow[t]{2}{*}{26 weeks } & 7 & 8.0 & 1 & 5.4 & 0.84 & 57 & 50 & 3.47 \\
\hline & & $3 ; 9$ & $0 ; 1$ & $0 ; 7$ & $0.6 ; 1.1$ & $33 ; 75$ & $37 ; 68$ & $2.4 ; 4.0$ \\
\hline \multirow[t]{2}{*}{52 weeks } & 2 & 5 & 0 & $\mathrm{I}$ & 0.38 & 31 & 30 & 2.2 \\
\hline & & $4 ; 8$ & $0 ; 0$ & I; 2 & $0.4 ; 0.4$ & $18 ; 42$ & $19 ; 40$ & $1.9 ; 2.4$ \\
\hline \multirow[t]{2}{*}{ Last visit } & 16 & 5.1 & 0.6 & 2.6 & 0.83 & $4 I$ & 43 & 2.9 \\
\hline & & $2 ; 8$ & $0 ; 0.3$ & $0 ; 3$ & $0.3 ; 1.3$ & $22 ; 63$ & $20 ; 67$ & $2.0 ; 3.5$ \\
\hline \multicolumn{9}{|l|}{ Etanercept } \\
\hline \multirow[t]{2}{*}{ Baseline } & 34 & II.I & 4.6 & 5.2 & 1.01 & 58 & 56 & 4.01 \\
\hline & & $3 ; 11$ & I; 7 & $2 ; 6$ & $0.8 ; 1.3$ & $45 ; 76$ & $40 ; 75$ & $3.4 ; 4.5$ \\
\hline \multirow[t]{2}{*}{26 weeks } & 19 & 4.4 & 1 & 1.5 & 0.58 & 36 & 36 & 2.77 \\
\hline & & $2 ; 5$ & $0 ; 1$ & $0 ; 3$ & $0.3 ; 0.9$ & $15 ; 54$ & $9 ; 53$ & $2.2 ; 3.4$ \\
\hline \multirow[t]{2}{*}{52 weeks } & 11 & 8.1 & 1.2 & 1.7 & 0.91 & 46 & 48 & 3.15 \\
\hline & & $4 ; 8$ & $0 ; 1$ & $0 ; 3$ & $0.5 ; 1.3$ & $33 ; 52$ & $41 ; 40$ & $2.6 ; 3.7$ \\
\hline \multirow[t]{2}{*}{ Last visit } & 44 & 5.2 & 1.1 & 1.9 & 0.65 & 36 & $4 I$ & 2.61 \\
\hline & & I; 6 & $0 ; 1$ & $0 ; 3$ & $0.0 ; 1.1$ & $10 ; 54$ & $14 ; 64$ & I.6; 3.6 \\
\hline \multicolumn{9}{|l|}{ Adalimumab } \\
\hline \multirow[t]{2}{*}{ Baseline } & 15 & 13.7 & 4.6 & 4.1 & 0.86 & 57 & 58 & 4.18 \\
\hline & & $4 ; 16$ & $2 ; 6$ & $2 ; 6$ & $0.3 ; 1.4$ & $4 I ; 72$ & $51 ; 77$ & $3.7 ; 4.4$ \\
\hline \multirow[t]{2}{*}{26 weeks } & 12 & 2.6 & 0.6 & 1.5 & 0.70 & 37 & 39 & 2.67 \\
\hline & & I; 4 & $0 ; 0.3$ & $0 ; 2$ & $0.0 ; 1.5$ & $6 ; 64$ & $8 ; 65$ & $2.0 ; 3.3$ \\
\hline \multirow[t]{2}{*}{52 weeks } & 5 & 2 & 1.0 & 1.8 & 0.66 & 29 & 48 & 2.4 \\
\hline & & $0 ; 3$ & $0 ; 0$ & $0 ; 0$ & $0.3 ; 1.0$ & $19 ; 40$ & $45 ; 59$ & $1.8 ; 2.6$ \\
\hline \multirow[t]{2}{*}{ Last visit } & 15 & 2.8 & 0.7 & 2.0 & 0.73 & 40 & 50 & 2.7 \\
\hline & & $\mathrm{I} ; 4$ & $0 ; 0.0$ & $0 ; 3.5$ & $0.2 ; 1.0$ & $16 ; 64$ & $28 ; 76$ & I.9; 3.4 \\
\hline$p$-value** & Baseline & 0.83 & 0.78 & 0.43 & 0.87 & 0.31 & 0.16 & 0.50 \\
\hline \multirow{3}{*}{$\begin{array}{l}\text { between the } \\
\text { groups }\end{array}$} & 26 weeks & 0.11 & 0.31 & 0.48 & 0.61 & 0.34 & 0.65 & 0.53 \\
\hline & 52 weeks & 0.17 & 0.65 & 0.77 & 0.58 & 0.67 & 0.51 & 0.44 \\
\hline & Last visit & 0.09 & 0.65 & 0.63 & 0.78 & 0.76 & 0.44 & 0.68 \\
\hline
\end{tabular}

Notes: Disease activity at baseline of 185 patients with psoriatic arthritis undergoing four different treatment strategies with TNF- $\alpha$ inhibitors, and on follow-up at 26 and 52 weeks and at last visit. Data are presented as means and quartiles on the line below. Number is lower than in Table I because of missing data. Data are presented as raw values without any corrections. No differences were observed between the two infliximab groups evaluated with Wilcoxon test. **Kruskal-Wallis rank sum test was used to compare all four groups.

Abbreviations: DAS, Disease Activity Score; Nr, numbers; SJC, swollen 28-joint count; TJC, tender 28-joint count; VAS, visual analog scale; DAS28, .

results, as does our study in collaboration with DANBIO where we demonstrated that a starting dose of $3.1 \mathrm{mg} / \mathrm{kg}$ had a favorable outcome. ${ }^{11}$ In the present study, only $20 \%$ of the patients needed to increase their doses of infliximab above $4 \mathrm{mg} / \mathrm{kg}$ and only a few individuals needed a higher dose than the recommended dose of $5 \mathrm{mg}$ per $\mathrm{kg}$ body weight. There was no standard definition of lack of efficacy which would necessitate increased dosage of infliximab, but the individual rheumatologist together with the respective patient assumed that a higher dosage could benefit the patient, whether that decision was made on joint or skin status of the disease, we do not have information on. Thus, if a low dose treatment schedule with infliximab is as effective as $5 \mathrm{mg} / \mathrm{kg}$, this gives rise to a serious discussion of the more economical, though still effective, dosage required.

In Iceland, 1-year treatment with etanercept and adalimumab costs approximately $€ 12-14.000$, while the yearly cost of the present treatment schedule of infliximab fixed 
Table 3 Changes in disease activity

\begin{tabular}{|c|c|c|c|c|c|c|c|c|}
\hline & $\mathbf{N r}$ & $\Delta$ CRP mg/L & $\Delta \mathrm{SJC}$ & $\Delta \mathrm{TJC}$ & $\triangle$ HAQ & $\Delta$ VAS pain & $\Delta$ VAS fatigue & $\Delta$ DAS28 \\
\hline \multicolumn{9}{|l|}{ Infliximab } \\
\hline \multicolumn{9}{|l|}{$<4$ mg/kg } \\
\hline \multirow[t]{2}{*}{26 weeks } & 27 & -4.9 & -2.2 & -2.7 & -0.25 & -21.3 & -20.1 & -1.05 \\
\hline & & $-7.0 ; 0.0$ & $-3.3 ;-0.8$ & $-5.0 ;-0.8$ & $-0.4 ; 0$ & $-38 ;-6.3$ & $-39 ;-0.8$ & $-1.7 ;-0.4$ \\
\hline \multirow[t]{2}{*}{52 weeks } & 16 & -1.8 & -3 & -2.5 & -0.08 & -23.6 & -12.7 & -0.81 \\
\hline & & $-8.5 ; \quad$ I.3 & $-6.5 ; 0.0$ & $-5.0 ; 0.5$ & $-4.4 ; 0.4$ & $-36 ; 7.5$ & $-28 ; 9.5$ & $-1.9 ; 0.6$ \\
\hline \multirow[t]{2}{*}{ Last visit } & 53 & -4.67 & -3.15 & -2.83 & -0.18 & -24.2 & -19.2 & -1.31 \\
\hline & & $-8.3 ; 1.0$ & $-5.0 ; 0.0$ & $-5.0 ;-1$ & $-05 ; 0.1$ & $-50 ; 7.0$ & $-4 I ; 2.8$ & $-2.3 ;-0.5$ \\
\hline \multicolumn{9}{|l|}{$>4$ mg/kg } \\
\hline \multirow[t]{2}{*}{26 weeks } & 7 & 0.71 & -2.7 & -4.0 & -0.21 & -13.9 & -24.3 & -0.9 \\
\hline & & $0.0 ; 3.5$ & $-5.5 ;-1.0$ & $-12 ; 1.0$ & $-0.6 ; 0.1$ & $-14 ;-2.0$ & $-26 ;-19$ & $-2.3 ; 0.1$ \\
\hline \multirow[t]{2}{*}{52 weeks } & 2 & -5.0 & -15 & 0.0 & 0.19 & -9.5 & -19.5 & -0.7 \\
\hline & & $-6.0 ;-4.0$ & $-2.3 ;-0.8$ & $-1.0 ; 1.0$ & $0.1 ; 0.3$ & $-17 ;-2.3$ & $-20 ;-19$ & $-1.3 ;-0.2$ \\
\hline \multirow[t]{2}{*}{ Last visit } & 11 & -7.2 & -2.45 & -5.91 & 0.01 & -24.6 & 29.3 & -1.39 \\
\hline & & $-13 ;-1.3$ & $-4.0 ; 0.0$ & $-9.0 ; 0.0$ & $-0.3 ; 0.4$ & $-44 ;-15$ & $-44 ;-21$ & $-2.8 ;-0.4$ \\
\hline \multicolumn{9}{|l|}{ Etanercept } \\
\hline \multirow[t]{2}{*}{26 weeks } & 16 & -3.8 & -2.6 & -3.0 & 0.43 & -20.1 & -17.2 & -1.31 \\
\hline & & $-5.3 ; \quad 1.3$ & $-5.5 ;-0.3$ & $-5.0 ;-2.0$ & $-0.5 ; 0.4$ & $-4 I ; 1.0$ & $-36 ;-1.5$ & $-2.1 ;-0.6$ \\
\hline \multirow[t]{2}{*}{52 weeks } & 9 & 2.2 & -2.8 & -2.6 & -0.32 & -20 & -16.4 & -0.65 \\
\hline & & $-3.0 ; 3.0$ & $-5.0 ;-0.5$ & $-48 ; 0$ & $-0.4 ;-0.4$ & $-30 ;-20$ & $-31 ;-22$ & $-0.7 ;-0.3$ \\
\hline \multirow[t]{2}{*}{ Last visit } & 23 & $-1.7 \mid$ & -2.38 & -2 & -0.29 & -21.1 & -15.4 & -1.40 \\
\hline & & $-5.0 ; 1.0$ & $-4.3 ; 0.0$ & $-4.0 ; 0.0$ & $-0.6 ;-0.1$ & $-30 ;-8.5$ & $-3 I ; I I$ & $-2.1 ; 0.7$ \\
\hline \multicolumn{9}{|l|}{ Adalimumab } \\
\hline \multirow[t]{2}{*}{26 weeks } & 10 & -4.8 & -4.2 & -3.2 & 0.04 & -17.5 & -26.2 & -1.4 \\
\hline & & $-7.2 ;-1.3$ & $-5.0 ;-1.5$ & $-4.0 ;-1.5$ & $0.1 ; 0.9$ & $-43 ; 9.3$ & $-46 ;-25$ & $-1.7 ;-0.5$ \\
\hline \multirow[t]{2}{*}{52 weeks } & 4 & -4.0 & -3.3 & -4.3 & -0.38 & -31 & -17 & -16 \\
\hline & & $-5.5 ;-2.5$ & $-6.0 ; 0.0$ & $-5 ;-2.3$ & $-0.6 ;-0.1$ & $-35 ;-27$ & $-19 ;-15$ & $-1.7 ;-1.6$ \\
\hline \multirow[t]{2}{*}{ Last visit } & 15 & -4.64 & -3.92 & -2.85 & -047 & -33.0 & -30.1 & -1.90 \\
\hline & & $-6.0 ;-1.5$ & $-5.3 ; 0.0$ & $-4.0 ;-1.0$ & $-0.9 ; 0.1$ & $-57 ;-5.8$ & $-57 ;-11$ & $-2.2 ;-1.5$ \\
\hline$p$-value ${ }^{* *}$ & 26 weeks & 0.18 & 0.44 & 0.95 & 022 & 0.81 & 0.93 & 0.94 \\
\hline between the & 52 weeks & 0.37 & 0.97 & 0.58 & 0.38 & 0.69 & 0.83 & 0.83 \\
\hline groups & Last visit & 0.50 & 0.66 & 0.38 & 0.22 & 0.84 & 0.54 & 0.74 \\
\hline
\end{tabular}

Notes: Changes in disease activity indexes ( $\Delta$ value) from baseline, of 185 patients with psoriatic arthritis undergoing four different treatment strategies with TNF- $\alpha$ inhibitors on follow-up at 26 and 52 weeks and at last visit. Data are presented as means and quartiles on the line below. Number is lower than in Table 2 because of missing data. No differences were observed between the two infliximab groups evaluated with Wilcoxon test. **Kruskal-Wallis rank sum test was used to compare all four groups. Abbreviations: DAS, Disease Activity Score; Nr, numbers; SJC, swollen 28-joint count; TJC, tender 28-joint count; HAQ, ; VAS, visual analog scale; DAS28, .

$200 \mathrm{mg}$ dosage every 8 weeks is less than $€ 8.300$. However, the dosage is increased in some patients, but only in few cases above $5 \mathrm{mg} / \mathrm{kg}$. The mean dosage of infliximab in our group of patients with PsA was $277 \mathrm{mg}$ or the equivalent of $€ 11.400$, which is still lower than if the dosage was the internationally recommended $5 \mathrm{mg} / \mathrm{kg}(€ 20,600)$. Several other variables need to be considered when performing complex economical evaluations. However, the drug cost is the single highest cost in this economical equation. Thus, selecting not only TNF inhibitors, but also strictly following the dosage with tight follow-up schedules, can save a considerable amount of money for the community, as this treatment is almost fully reimbursed in Iceland. In addition, the Icelandic Social Insurance Administration invites annual or biannual tenders that further reduce the cost of biological treatment in rheumatology care in Iceland.
The present study has several limitations, as do other observational studies. However, the study is based on a nationwide clinical registry and reflects routine care and clinical decision-making concerning nationwide treatment with biologics in patients with PsA. The results strongly indicate that a dose lower than $5 \mathrm{mg} / \mathrm{kg}$ of infliximab, as indicated in several international guidelines, is effective in bringing patients with PsA into low stage disease activity or remission. However, we must take into consideration the fact that our high dose patients will be enriched with patients who were non-responders to infliximab. This would tend to favor the low dose group in respect to treatment response. Furthermore, as this is an observational registry study, there are missing values in the registry as well as the fact that we do not have reliable data on concomitant medicine such as steroids or methotrexate. Therefore, cautious interpretation 


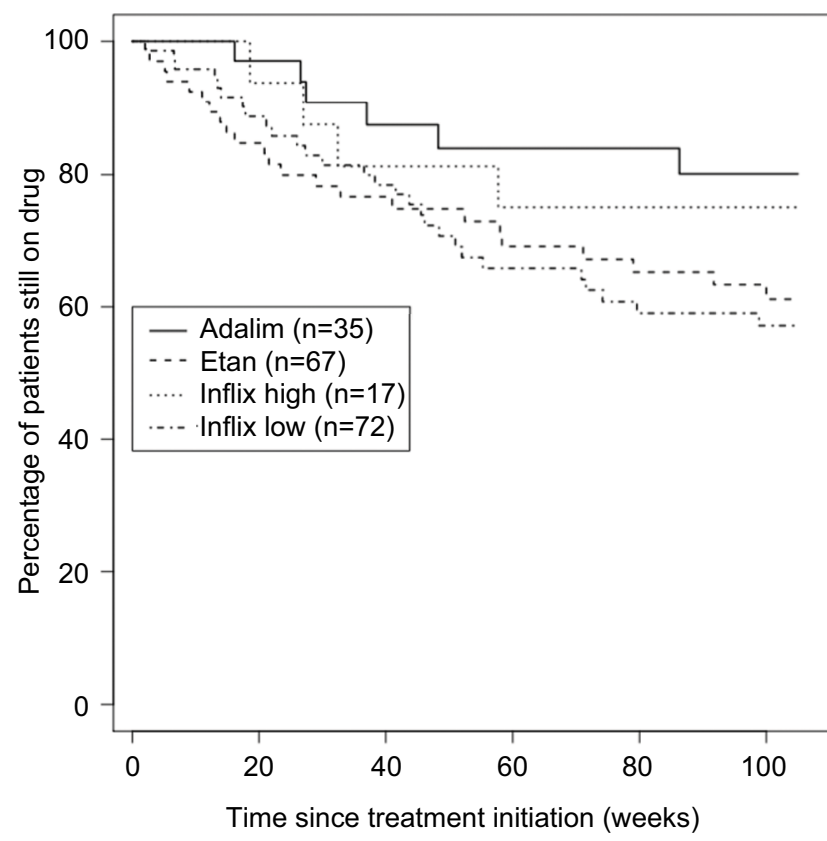

Figure I Drug survival plots (Kaplan-Meier) for 185 patients with psoriatic arthritis undergoing four different treatment strategies with TNF- $\alpha$ inhibitors over I04-week period.

Abbreviations: Adalim, adalimumab; Etan, etanercept; Inflix, infliximab. treatment groups, as if this was a randomized controlled trial, even though it was not.

In respect to treatment effects, a low dosage of infliximab with possible escalating dosage is acceptable for the majority of PsA patients who are in need of biological treatment, and as effective as standard doses of adalimumab and etanercept in patients with PsA. Drug selection can influence the economic burden of biological treatment in PsA.

\section{Acknowledgments}

Thanks to Elinborg Stefansdottir, RN, for all practical help. Thanks to all those patients who record their symptoms on regular visits in ICEBIO, and to all rheumatologists in Iceland who are part of the ICEBIO group: Erlendsson K, Grondal G, Ingvarsson RF, Jonsson H, Jonsdottir T, Love TJ, Ludviksson BR, Reynisdottir GB, Steinsson K, Tomasson G, Valtysdottir $\mathrm{S}$, and Vikingsson A. The study was partly funded by a study grant from The Icelandic Society for Rheumatology.

The study was presented as a poster (2227) at the ACR/ ARHP Annual Meeting, November 9-14, 2012, Washington, DC, USA.

\section{Disclosure}

is advised when comparing the results of the present study. Therefore, the present findings show the need for further research by designing a multicenter, randomized controlled trial, where radiological follow-up of joint damage should be included and with at least two parallel arms with both the recommended doses of infliximab, i.e., $5 \mathrm{mg} / \mathrm{kg}$, as well as some other TNF inhibitors, i.e., etanercept, adalimumab, golimumab or certolizumab. In addition, long-term followup studies are needed to describe drug survival, drug tolerance and effectivity in respect to a lower dose approach of infliximab in comparison to the 5 and $10 \mathrm{mg} / \mathrm{kg}$ body weight that has already been described in the IMPACT studies. ${ }^{5,6}$ Future studies should also include the economic aspect of the issue.

Interestingly, two observations that increase the validity of the present results are: firstly, those patients who needed to escalate their infliximab dose above $4 \mathrm{mg} / \mathrm{kg}$ had a significantly lower mean body weight compared to those who responded to the lower dosage. Thus, it was not the fact that patients were overweight, which has frequently been described in patients with psoriasis ${ }^{16}$ and PsA, ${ }^{17}$ which drove the escalation of the infliximab dosage. Secondly, and to our surprise to some extent, the disease activity at baseline evaluated with CRP, number of tender and swollen joints as well as the VAS of pain and fatigue, was similar in all four
The authors report no conflicts of interest in this work.

\section{References}

1. Love TJ, Gudbjornsson B, Gudjonsson JE, Valdimarsson H. Psoriatic arthritis in Reykjavik, Iceland: prevalence, demographics, and disease course. J Rheumatol. 2007;34(10):2082-2088.

2. Gossec L, Smolen JS, Gaujoux-Viala C, et al. European League Against Rheumatism recommendations for the management of psoriatic arthritis with pharmacological therapies. Ann Rheum Dis. 2012;71(1):4-12.

3. Coates LC, Kavanaugh A, Mease PJ, et al. Group for Research and Assessment of Psoriasis and Psoriatic Arthritis 2015 Treatment Recommendations for Psoriatic Arthritis. Arthritis Rheumatol. 2016;68(5):1060-1071.

4. [Icelandic guideline for using boDMARDs in PsA]. Available from https://www.landspitali.is/fagfolk/kliniskar-leidbeiningar/leit-i-kliniskum-leidbeiningum/. Accessed April 23, 2018.

5. Antoni CE, Kavanaugh A, Kirkham B, et al. Sustained benefits of infliximab therapy for dermatologic and articular manifestations of psoriatic arthritis: Results from the infliximab multinational psoriatic arthritis controlled trial (IMPACT). Arthritis Rheum. 2005;52(4):1227-1236.

6. Antoni C, Krueger GG, de Vlam K, et al. Infliximab improves signs and symptoms of psoriatic arthritis: results of the IMPACT 2 trial. Ann Rheum Dis. 2005;64(8):1150-1157.

7. Gottlieb AB, Evans R, Li S, et al. Infliximab induction therapy for patients with severe plaque-type psoriasis: a randomized, double-blind, placebo-controlled trial. J Am Acad Dermatol. 2004;51(4):534-542.

8. Cauza E, Spak M, Cauza K, et al. Treatment of psoriatic arthritis and psoriasis vulgaris with the tumor necrosis factor inhibitor infliximab. Rheumatol Int. 2002;22(6):227-232.

9. Di Renzo L, Saraceno R, Schipani C, Chimenti S, De Lorenzo A. Why $3 \mathrm{mg} / \mathrm{kg}$ instead of $5 \mathrm{mg} / \mathrm{kg}$ of infliximab should work in psoriatic arthritis? J Dermatol. 2009;36(12):666-668.

10. Tenga G, Goeb V, Lequerre T, et al. A $3 \mathrm{mg} / \mathrm{kg}$ starting dose of infliximab in active spondyloarthritis resistant to conventional treatments is efficient, safe and lowers costs. Joint Bone Spine. 2011;78(1):50-55. 
11. Glintborg B, Gudbjornsson B, Krogh NS, et al. Impact of different infliximab dose regimens on treatment response and drug survival in 462 patients with psoriatic arthritis: results from the nationwide registries DANBIO and ICEBIO. Rheumatology (Oxford). 2014;53(11):2100-2109.

12. Jois RN, Leeder J, Gibb A, et al. Low-dose infliximab treatment for ankylosing spondylitis--clinically- and cost-effective. Rheumatology (Oxford). 2006;45(12):1566-1569.

13. Yates M, Keat A, Gaffney K. Do low-dose anti-TNF regimens have a role in patients with ankylosing spondylitis? Rheumatology (Oxford). 2016;55(5):769-772.

14. DANBIO [database on the Internet]. Danish Rheumatological Database. Glostrup: Denmark. Available from: https://danbio-online.dk. Accessed April 3, 2018.
15. Kristensen LE, Gulfe A, Saxne T, Geborek P. Efficacy and tolerability of anti-tumour necrosis factor therapy in psoriatic arthritis patients: results from the South Swedish Arthritis Treatment Group register. Ann Rheum Dis. 2008;67(3):364-369.

16. Carrascosa JM, Rocamora V, Fernandez-Torres RM, et al. Obesity and psoriasis: Inflammatory nature of obesity, relationship between psoriasis and obesity, and therapeutic implications. Actas Dermosifiliogr. 2014;105(1):31-44.

17. Strohal R, Kirby B, Puig L, et al. Psoriasis beyond the skin: an expert group consensus on the management of psoriatic arthritis and common co-morbidities in patients with moderate-to-severe psoriasis. J Eur Acad Dermatol Venereol. 2014;28(12):1661-1669.
Psoriasis: Targets and Therapy

\section{Publish your work in this journal}

Psoriasis: Targets and Therapy is international, peer-reviewed, open access journal focusing on psoriasis, nail psoriasis, psoriatic arthritis and related conditions, identification of therapeutic targets and the optimal use of integrated treatment interventions to achieve improved outcomes

\section{Dovepress}

and quality of life. Visit http://www.dovepress.com/testimonials.php to read real quotes from published authors. 